\title{
A FORMAÇÃO PARA ENSINAR MATEMÁTICA OFERECIDA NO CURSO NORMAL DE SÃO PAULO E AS INFLUÊNCIAS QUE ORIENTAVAM A DIREÇÃO DESSE CURSO AO LONGO DOS PRIMEIROS ANOS DE SUA EXISTÊNCIA
}

\author{
TRAINING TO TEACH MATHEMATICS OFFERED IN THE NORMAL \\ COURSE OF SÃO PAULO AND THE INFLUENCES THAT CONTROLLED THE \\ DIRECTION OF THIS COURSE THROUGHOUT THE FIRST YEARS OF ITS \\ EXISTENCE
}

Edda Curi (Universidade Cruzeiro do Sul)

Cintia Ap. Bento dos Santos (Universidade Cruzeiro do Sul)

\begin{abstract}
Resumo: Este artigo, resultado de pesquisa realizada, tem como finalidade identificar como o Curso Normal de São Paulo, desde sua criação até a década de 1930 formou professores para atuar no período de escolarização que hoje se denomina anos iniciais do Ensino Fundamental. Por meio de uma análise documental discute como se dava a preparação para ensinar Matemática, buscando indícios das influências que orientavam a direção desse curso durante os primeiros anos de sua existência. Foram analisados documentos elaborados por órgãos normativos e instituições formadoras, manuais didáticos e revistas destinadas ao ensino e à formação do professor. A pesquisa evidenciou, no Período do Império, o predomínio de uma formação genérica, assentada nos fundamentos da moral e bons costumes, o aumento da quantidade de disciplinas sob a influência do positivismo na época da Proclamação da República, e o foco nos Fundamentos da Educação e a influência da Psicologia a partir de 1920.
\end{abstract}

Palavras chave: formação de professores. Conhecimentos matemáticos. curso normal

Abstract: This article, result of research conducted, aims to identify how the Normal course of São Paulo from its creation until the 1930s formed teachers for work in the period of schooling that today is called the cycle I of the early years of elementary education. Through a documentary discusses how analysis was preparing to teach mathematics, seeking evidence of influences that controlled the direction of the course during the first years of its creation. Were analysed documents established by regulatory agencies and institutions forming, didactic manuals and magazines intended for teaching and teacher training. The survey showed, in the period of the Empire, the predominance of a generic training, seated in the foundations of morals and good customs, increased amount of disciplines under the influence of positivism at the time of the proclamation of the Republic, and the focus on the fundamentals of education and the influence of Psychology from 1920.

Keywords: training of teachers, math skills, normal course

\begin{tabular}{|l|l|l|l|l|l|}
\hline Interfaces da Educ. & Paranaíba & v. 2 & n. 5 & p.84-98 & 2011 \\
\hline
\end{tabular}




\section{Introdução}

Por nossa prática docente sabemos que é muito comum professores dos anos finais do Ensino Fundamental atribuírem os problemas de aprendizagem dos alunos em Matemática aos professores dos anos iniciais desse segmento de ensino. Esses professores formados em nível médio, no antigo Curso Normal e mais recentemente em curso superior, são identificados como profissionais que, embora entendam muito de crianças, não têm conhecimentos profundos dos conteúdos das disciplinas que ensinam, mais ainda que seus saberes matemáticos são próximos daquilo que ensinam.

Além disso, na pesquisa de Curi (2004) fica evidente que existem mitos de que esses professores procuram cursos de magistério para crianças porque não gostam de Matemática ou ainda que Matemática não é para mulheres e, portanto para seguir uma profissão feminina como essa não é preciso saber Matemática. Porém, a autora, ressalta, também, que a formação inicial de professores que atuam nos anos iniciais nem sempre contempla os aspectos essenciais para que estes ensinem Matemática.

Em se tratando de pesquisa, podemos dizer que as investigações sobre formação de professores vêm tomando corpo no Brasil nos últimos anos. Além da quantidade considerável de trabalhos, há uma diversidade de enfoque sobre o tema, mas há poucas pesquisas que considerem aspectos históricos da formação do professor dos anos iniciais no que se refere à formação para ensinar Matemática. É preciso alargar a discussão na comunidade de educadores matemáticos.

Com a finalidade de apresentar mais elementos que contribuam para a ampliação desse debate, revisitamos alguns dados da tese de doutorado de uma das autoras ${ }^{1}$ deste texto selecionando para discussão informações contidas no trabalho referentes aos cursos de formação de professores para atuar nos anos iniciais do Ensino Fundamental desde sua criação até meados da década de 1930. Um dos objetivos da referida tese era identificar em diferentes momentos da história da educação brasileira se a formação de professores para atuar nos anos iniciais do ensino fundamental os preparava para ensinar Matemática. Foram analisados na tese de doutorado o Programa da Escola Normal de São Paulo de 1902, algumas Revistas de Ensino do início do século XX focalizando orientações para o ensino de Matemática e o livro Psicologia da Aritmética de Thorndike publicado em 1929, além de outros manuais de ensino surgidos após esse período. No entanto, esse não era o objetivo principal dessa tese de doutorado e o resgate histórico tinha como finalidade contextualizar a formação de professores desde a criação do Curso Normal no Brasil. Muitos documentos e manuais didáticos do período inicial do Curso Normal de São Paulo foram pesquisados, mas os dados não foram incluídos na versão final da referida tese, por não ser o foco da pesquisa.

O material não usado na tese de doutorado estava guardado e foi resgatado para ser analisado neste artigo com objetivo de ampliar o debate sobre a relação da história com a formação inicial de professores que atuam nos anos iniciais do Ensino Fundamental verificando se essa formação contempla aspectos para ensinar Matemática.

A pesquisa histórica possibilita a reconstrução de um objeto de estudo que, por um lado, às vezes é muito focalizado, mas por outro lado pouco conhecido. A análise que nos

${ }^{1}$ Tese de doutorado defendida na PUC/SP em 2004, sob orientação de Célia Maria Carolino Pires.

\begin{tabular}{|l|l|l|l|l|l|}
\hline Interfaces da Educ. & Paranaíba & v. 2 & n. 5 & p.84-98 & 2011 \\
\hline
\end{tabular}


propomos fazer pode dar pistas para melhor compreensão das dificuldades dos atuais Cursos de Pedagogia com o ensino de Matemática.

Cabe destacar que na pesquisa de campo da tese de doutorado, houve várias visitas ao Centro de Referência em Educação Mario Covas e foram manuseados, analisados e xerocados, quando possível, documentos e manuais didáticos de Matemática do início do século XX e também Revistas de Ensino desse período. Nessa análise havia clareza de que o objetivo da pesquisa de doutorado era de identificar possíveis marcas que esse material poderia ter deixado na formação dos professores daquela época. A autora buscou todas as referências que tinha notícia, não mediu esforços, mas deixou de lado materiais que foram usados neste artigo, como grades curriculares do Curso Normal em diferentes épocas, lista de pontos para o exame final do Curso Normal, lista de pontos para concurso de ingresso no magistério, alguns manuais didáticos do início do século XX. As Revistas de Ensino foram usadas com outro foco diferente do apresentado na tese.

Nossa formação como professoras de Matemática e nossa trajetória inicial como professoras de crianças e jovens da rede pública de São Paulo e trajetória atual como formadoras de professoras nos dá elementos para a discussão realizada neste texto, mesmo tendo consciência que não temos formação histórica.

Este artigo se faz pautado e toma como referencial teórico os estudos de Tardif (2000), pois este autor considera que os saberes docentes evoluem com o passar do tempo e de Shulman (1992) sobre o que o autor denomina de "paradigma perdido".

Tardif (2000) afirma que "os conteúdos que os professores ensinam" e a "sua maneira de ensinar" evoluem com o tempo e com as mudanças da sociedade. Revela ainda que a Pedagogia, a Didática, as concepções de Aprendizagem e de Ensino dependem intrinsecamente da história e da cultura da sociedade e das próprias hierarquias que predominam na educação. $\mathrm{O}$ autor revela que os saberes disciplinares correspondem aos saberes que a sociedade dispõe e que são incorporados nas instituições de ensino na forma de disciplinas. Conclui que as disciplinas presentes nos currículos emergem dos grupos produtores de saberes, mas incorporam concepções dos formadores e da instituição de ensino que estudaram e que atuam e da sociedade.

Shulman (1992) revela que o aumento de pesquisas em Educação sobre o "como ensinar" teve conseqüências na formação dos professores, na medida em que as instituições formadoras passaram a privilegiar os procedimentos de ensino em detrimento do estudo dos objetos de ensino. Tal fato é denominado por ele de "paradigma perdido", ou seja, a mudança do foco "o que ensinar" para "como ensinar".

Para atingirmos o objetivo a que nos propomos neste artigo e levando em conta nosso referencial teórico, utilizaremos como técnica de metodologia de pesquisa a análise documental que nos permitirá observar como se deu a evolução da formação inicial de professores dos anos iniciais em se tratando dos conteúdos de Matemática no período de 1835 a 1930.

A análise documental ou pesquisa documental, segundo Pádua (2002) é aquela realizada a partir de documentos que podem ser contemporâneos ou retrospectivos, mas que são considerados cientificamente aceitos, ou seja não são fraudados. Para a autora, um documento se pauta com conhecimento fixado materialmente que pode ser utilizado para consulta ou estudo ou prova.

\begin{tabular}{|l|l|l|l|l|l|}
\hline Interfaces da Educ. & Paranaíba & v. 2 & n. 5 & p.84-98 & 2011 \\
\hline
\end{tabular}


Ludke e André (1986) apontam vantagens para utilização de pesquisa documental, entre elas que os documentos apresentam uma fonte de informação importante e diversificada, que os dados permanecem inalterados ao longo do tempo, o que permite consulta permanente, implica baixo custo e ainda permite o acesso das informações mesmo sem a pessoa que produziu.

As autoras defendem a existência de procedimentos metodológicos para esse tipo de pesquisa, entre eles destacam a discussão a respeito do tipo de documento que será selecionado, ou seja, serão documentos oficiais ou técnicos, ou ambos; a análise das informações contidas nos documentos selecionados, entre elas a análise de cunho interpretativo e a forma de registro, ou seja, a escrita em forma de texto.

Para este artigo, analisaremos documentos oficiais como grades curriculares e Programas da Escola Normal da Província de São Paulo, listas de pontos publicadas para o exame final dessa escola e outras destinadas a concursos de ingresso de professores no período de 1835 até meados de 1930, livros de Matemática e Revistas destinadas ao ensino, buscando identificar indícios da formação do professor para ensinar Matemática. Como já foi dito, grande parte desse material não tinha sido analisado na referida tese de doutorado, no caso das Revistas de Ensino e no livro de Tordnike foi dado outro foco diferente da tese. Foram acrescentados os livros de Trajano, Souza Reis e de Dordal de época anterior a Tordnike. Seguiremos uma ordenação cronológica, partindo da criação do Curso Normal, no Brasil, até meados da década de 30, procurando sintetizar o que foi possível investigar sobre a formação de professores dos anos iniciais para ensinar matemática, analisando a trajetória do Curso Normal que se iniciou na Província de São Paulo e também o que era veiculado em livros de Matemática que possivelmente eram usados na formação desses professores e informado nas revistas de Ensino do início do século XX.

\section{Algumas informações sobre a criação do Curso Normal no Brasil}

Os primeiros cursos de formação de professores no Brasil denominaram-se Curso Normal. O primeiro deles foi criado em 15 de outubro de 1827 pela Primeira Lei da Educação do Brasil. A finalidade desse curso era formar professores para as denominadas escolas de Primeiras Letras ${ }^{2}$. No entanto, o primeiro Curso Normal só foi instalado sete anos após a sua criação, em Niterói no ano de 1835. O segundo curso foi criado na província da Bahia em 1842 e o terceiro em 1847 na Província São Paulo. Até o ano de 1867, vinte anos depois, existia apenas um único Curso Normal da Província de São Paulo.

\section{A preocupação com a moral e os bons costumes na época do Império}

Nesse item analisaremos a grade curricular do Curso Normal da Província de São Paulo, a lista de pontos para o exame final que era realizado nessa escola e a lista de temas referentes às conferências de Barão Gérando, publicadas em livro usado durante muitos anos em várias Províncias brasileiras no Curso Normal.

Autores como Monarcha (1999) e Tanuri (2000) discutem a formação de professores nas primeiras escolas de magistério brasileiras e destacam a predominância da preocupação com a moral e os bons costumes.

${ }^{2}$ Denominação das escolas que desenvolviam o que se refere hoje aos anos iniciais do Ensino Fundamental.

\begin{tabular}{|l|l|l|l|l|l|}
\hline Interfaces da Educ. & Paranaíba & v. 2 & n. 5 & p.84-98 & 2011 \\
\hline
\end{tabular}


Monarcha (1999) constatou que na época do Império, a Escola Normal da Província de São Paulo publicava uma lista de pontos destinada aos alunos para se prepararem para os exames finais. Nessa lista é possível constatar a preocupação com a caligrafia, com métodos disciplinares, com a moral e os bons costumes dos professores. Não havia nenhuma inclusão de conteúdos matemáticos, embora nas grades curriculares desse curso houvessem disciplinas de Aritmética e Sistema Métrico. Essa constatação nos faz conjecturar que as disciplinas eram menos importantes do que os temas apontados na lista de pontos, pois não havia indicação de conteúdos dessas disciplinas destacados na lista de pontos para os exames finais. O quadro 1 , apresenta a lista de pontos citada.

\section{Quadro 1 - Lista de pontos para os Exames da Escola Normal da Província de São Paulo}

Fonte: Monarcha (1999)

I Pedagogia

$1 \mathrm{O}$ que seja pedagogia, qual sua matéria e em quantas partes se divide seu estudo;

2. Educação e Instrução;

3. Espécies de Educação;

4. Educação Física;

5. Educação Intelectual;

6. O professor e seus predicados;

7. A escola e suas condições materiais;

8. Mobília e utensílios da escola;

9. Métodos de ensino;

10. Penas e recompensas na escola;

11. Métodos disciplinares na escola;

12. Métodos de leitura.

II Doutrina Cristã

1. O que seja doutrina cristã e de quantas partes consta seu catecismo;

2. Profissão de fé católica;

3. O Credo;

4. Mandamentos da Lei de Deus;

5. Mandamentos da Santíssima Lei da Igreja;

6. Sacramentos da Lei da Graça;

7. Sacramentos em geral;

8. Sacramentos do Batismo;

9. Oração em geral;

10. Oração dominical e outras;

11. Sacramento da Eucaristia;

12. Os pecados e virtudes.

III Caligrafia

1. Letras primitivas e letras derivadas;

2. Formação das letras;

3. Letras maiúsculas e minúsculas e seus usos;

\begin{tabular}{|l|l|l|l|l|l|}
\hline Interfaces da Educ. & Paranaíba & v. 2 & n. 5 & p.84-98 & 2011 \\
\hline
\end{tabular}


4. Bastardo, bastardinho, cursiva;

5. Modo de aparar a pena;

6. Posição do corpo, modo de pegar a pena, colocação do papel ou do livro;

7. Modos de traçar as letras;

8. Métodos de escrever;

9. Método da letra cursiva;

10. Primeiras lições de escrita;

11. Inclinação das letras;

12. União das letras e espaços entre as palavras, bem com a divisão delas no fim da linha.

Ao analisar essa lista de pontos fica bastante claro a influência iluminista no Curso Normal da Província de São Paulo.

Segundo Tanuri (2000), a influência iluminista predominava no ensino da época da monarquia, visando a regulação de condutas, buscando desenvolver comportamentos pessoais e sociais compatíveis com a monarquia instalada.

A autora destaca ainda que os programas das disciplinas do Curso Normal de várias Províncias brasileiras eram rudimentares, não ultrapassando o nível dos conteúdos que deveriam ser ensinados nas Escolas de Primeiras Letras. Revela ainda que a formação pedagógica no Curso Normal era limitada a uma disciplina denominada Métodos de Ensino, que devido à consagração do ensino mútuo ${ }^{3}$ reduzia o preparo profissional do professor à compreensão desse método.

Mas, para ser professor na Província de São Paulo não era preciso nem ao menos freqüentar o Curso Normal. Segundo Monarcha (1999) e Tanuri (2000), se um cidadão com moral e bons costumes exercesse o magistério por dois anos e fosse aprovado em concurso promovido pela Província, se tornaria professor vitalício. Bastava que o cidadão lesse corretamente, escrevesse com caligrafia satisfatória, efetuasse as quatro operações, mesmo com dificuldades ou com alguns erros, e recitasse de cor as Orações da Igreja para ser aprovado nesse tipo de concurso.

Tanuri (2000) informa que o livro do Barão Gérando era usado no Curso Normal em várias Províncias no período do Império. Esse livro foi escrito na França e traduzido no Brasil. O livro era composto de uma lista de conferências. Como é possível verificar no quadro 2, os temas das conferências eram voltados à formação da personalidade do professor. Destacam-se temas como a Educação Religiosa, a Educação Moral, a dignidade e a qualidade necessárias ao professor da escola de Primeiras Letras. Esse livro era usado na Província de São Paulo.

\section{Quadro 2 - Temas de conferência do livro de Barão Gérando}

Fonte - Tanuri (2000)

$1 \quad$ Dignidade das funções dos professores de primeiras letras

2 Disposição e qualidades necessárias ao professor de ensino primário

\footnotetext{
${ }^{3} \mathrm{O}$ ensino mútuo era utilizado na Europa e permitia que um único professor ensinasse a muitos alunos. Até então cada professor ensinava particularmente apenas para um aluno.
}

\begin{tabular}{|l|l|l|l|l|l|}
\hline Interfaces da Educ. & Paranaíba & v. 2 & n. 5 & p.84-98 & 2011 \\
\hline
\end{tabular}




\begin{tabular}{|c|c|}
\hline 3 & Educação nas escolas primárias \\
\hline 4 & Educação Física \\
\hline 5 & $\begin{array}{l}\text { Educação intelectual- como pode o professor de primeiras letras cultivar a } \\
\text { atenção, a imaginação e a memória }\end{array}$ \\
\hline 6 & $\begin{array}{l}\text { Continuação da matéria antecedente - como pode o professor de primeiras letras } \\
\text { formar o juízo e a razão de seus alunos }\end{array}$ \\
\hline 7 & $\begin{array}{l}\text { Continuação da matéria antecedente - como pode o professor de primeiras letras } \\
\text { cultivar a instrução nas escolas de primeiras letras }\end{array}$ \\
\hline 8 & $\begin{array}{l}\text { Continuação da matéria antecedente - como pode o professor de primeiras letras } \\
\text { cultivar o método na instrução elementar }\end{array}$ \\
\hline 9 & Educação Moral nas escolas de primeiras letras \\
\hline 10 & $\begin{array}{l}\text { Continuação da matéria antecedente - como pode inspirar o professor de } \\
\text { primeiras letras aos discípulos o sentimento de seus deveres }\end{array}$ \\
\hline 11 & Educação Religiosa - parte que nela deve tomar o professor de primeiras letras \\
\hline 12 & Com procede o professor de primeiras letras no ensino dos deveres \\
\hline 13 & $\begin{array}{l}\text { Como trabalha o professor de primeiras letras para fortificar o caráter dos } \\
\text { meninos }\end{array}$ \\
\hline 14 & Algumas molas da educação - hábito e imitação \\
\hline 15 & Algumas molas da educação - trabalho e ordem \\
\hline 16 & Últimos conselhos aos mestres de primeiras letras. \\
\hline
\end{tabular}

Constatamos que tanto na lista de pontos para os exames da Escola Normal de São Paulo como na lista de temas de conferência do livro do Barão Gérando há predominância da formação voltada ao desenvolvimento da moral e dos bons costumes do professor. Como já foi dito, nas grades curriculares do Curso Normal da Província de São Paulo englobava, nessa época, as disciplinas de Aritmética e Geometria e que em 1875 os conteúdos relativos ao Sistema Métrico Decimal foram incluídos na disciplina de Aritmética. Em nenhuma dessas duas listas de temas há aspectos que evidenciem a preparação dos alunos da Escola Normal da Província de São Paulo para ensinar Matemática.

3. A influência do positivismo no Curso Normal de São Paulo, nos livros de Matemática e o surgimento das revistas de ensino.

A influência do Positivismo ${ }^{4}$ acarretou mudanças no Curso Normal da Província de São Paulo que incorporou muitas disciplinas de cunho científico, aumentando o os temas ligados à Matemática, incluindo Álgebra, Trigonometria e Escrituração Mercantil.

\footnotetext{
${ }^{4} \mathrm{O}$ positivismo opôs-se às abstrações da teologia e da metafísica. Ideologia e movimento filosófico fundado por Auguste Comte, o positivismo tem como base teórica os três pontos seguintes: (1) todo conhecimento do mundo material decorre dos dados "positivos" da experiência, e é somente a eles que o investigador deve aterse; (2) existe um âmbito puramente formal, no qual se relacionam as idéias, que é o da lógica pura e da matemática; e (3) todo conhecimento dito "transcendente" -- metafísica, teologia e especulação acrítica -- que se situa além de qualquer possibilidade de verificação prática, deve ser descartado.
}

\begin{tabular}{|l|l|l|l|l|l|}
\hline Interfaces da Educ. & Paranaíba & v. 2 & n. 5 & p.84-98 & 2011 \\
\hline
\end{tabular}


Quadro 3 - Grade Curricular da Escola Normal de São Paulo. Fonte: Anuário Estatístico do Estado de São Paulo de 1895

\begin{tabular}{|l|l|}
\hline Cadeira $^{\mathbf{5}}$ & $\begin{array}{l}\text { Horas de trabalho por } \\
\text { semana, } \mathbf{1}^{\mathbf{0}} \mathbf{e} \mathbf{2}^{\mathbf{0}} \text { anos }\end{array}$ \\
\hline Portuguez & 2 \\
\hline $\begin{array}{l}\text { Portuguez e História da } \\
\text { Língua }\end{array}$ & 2 \\
\hline Francez & 2 \\
\hline Latim & 2 \\
\hline Inglez & 2 \\
\hline Aritmética e álgebra & 1 \\
\hline Geometria e trigonometria & 1 \\
\hline Astronomia & 1 \\
\hline Mecânica & 1 \\
\hline Física e Química & 2 \\
\hline História Natural & 2 \\
\hline Astronomia e fisiologia & 1 \\
\hline Geografia & 2 \\
\hline História & 2 \\
\hline $\begin{array}{l}\text { Economia Política e } \\
\text { Educação Cívica }\end{array}$ & 1 \\
\hline $\begin{array}{l}\text { Pedagogia e Direção de } \\
\text { Escola }\end{array}$ & 1 \\
\hline Caligrafia e Desenho & 1 \\
\hline
\end{tabular}

\begin{tabular}{|l|l|}
\hline Disciplinas & $\begin{array}{l}\text { Horas de trabalho por } \\
\text { semana } \\
\mathbf{1}^{\mathbf{0}} \text { ano/2 }\end{array}$ \\
\hline Escrituração Mercantil & $2 / 2$ \\
\hline Economia Doméstica & $3 / 2$ \\
\hline $\begin{array}{l}\text { Exercícios Militares e } \\
\text { Ginástica }\end{array}$ & $2 / 3$ \\
\hline Trabalhos manuais & $2 / 2$ \\
\hline Música & $6 / 6$ \\
\hline
\end{tabular}

Observando essa grade é possível constatar o grande número de disciplinas, principalmente as de cunho científico, ao contrário do foco dado ao Curso Normal no período anterior.

${ }^{5}$ Era denominada de Cadeira, a disciplina em que havia um professor "efetivo" para ministrá-la.

\begin{tabular}{|l|l|l|l|l|l|}
\hline Interfaces da Educ. & Paranaíba & v. 2 & n. 5 & p.84-98 & 2011 \\
\hline
\end{tabular}


A análise dos livros de Matemática que priorizavam o treino de habilidades estritamente técnicas, uma programação extensa centrada em exercícios também revela a influência do positivismo.

Os livros utilizados nesta época como os de Trajano (1880), de Dordal (1901) e de Souza Reis (1919) tinham grande quantidade de exercícios aritméticos, com ênfase nos cálculos com números naturais e racionais na forma fracionária (Curi, 2005). A formação dos alunos era voltada ao trabalho no comércio e esse foco fazia com que os autores incluíssem entre os temas trabalhados o estudo de proporcionalidade, porcentagem, regra de três e juros. Esses temas eram trabalhados tanto nos livros destinados ao Curso Normal como nos dedicados aos alunos dos Grupos Escolares ${ }^{6}$.

Embora não houvesse indicação explicita que o livro Arithmetica Progressiva de autoria de Trajano se destinava ao Curso Normal, encontramos no prefácio da segunda edição desse livro publicada em 1880, comentários escritos por diversos formadores de cursos normais, o que permite conjecturar que esse livro era usado nesses cursos.

Trajano apresentava respostas e resolução dos exercícios propostos. Em seu livro Arithmetica Progressiva desenvolvia os seguintes conteúdos matemáticos: Números naturais, racionais, operações, medidas de comprimento, de massa e de capacidade, área, raiz quadrada, proporcionalidade, juros, porcentagens. Destaca-se a forma didática do texto. A teoria seguida de exercícios numéricos, iniciando com exercícios resolvidos com explicação passo a passo, depois uma lista de exercícios sem resolução, mas com resposta e por último outra lista de exercícios, porém sem respostas. Não havia demonstração de propriedades, apenas exemplos numéricos de sua validade.

$\mathrm{O}$ que se pode verificar hoje, é que ainda existem muitos autores de livros de Matemática que usam essa forma didática para organizar suas obras.

No texto de abertura da referida Edição, Trajano apontava problemas relativos ao ensino de Aritmética. Nele o autor afirmava que as pessoas, no geral, sabiam pouca Matemática e que, mesmo as mais inteligentes, não sabiam dispor os termos de uma proporção ou somar frações.

Analisando o texto de Trajano é possível conjecturar que o problema referente ao ensino de Matemática em nosso país vem de longa data, pois desde o final do século XIX, autores de livros de Matemática apontavam problemas com o ensino dessa área do conhecimento.

Segundo Curi (2005), o livro de autoria de Ramom Roca Dordal ${ }^{7}$ destacava na capa sua utilização no Curso Normal de São Paulo. O autor chama atenção para a solução dos 2000 exercícios e dos 1000 problemas relativos às quatro operações aritméticas com números naturais e racionais, proporção e regra de três.

Segundo essa autora, o grande número de edições dos livros de Trajano (84 edições) e de Souza Reis (54 edições) e os conteúdos desenvolvidos nesses livros permitem inferir que, por muitos anos, os cursos que formavam professores para atuar no início da aprendizagem centravam o ensino de Matemática na Aritmética.

\footnotetext{
${ }^{6}$ Denominação dada à escola que tratava do ensino que corresponde hoje ao período dos anos iniciais do ensino fundamental.

${ }^{7}$ Livro catalogado no Centro de Referência em Educação Mario Covas, no acervo da Escola Normal Caetano de Campos.
}

\begin{tabular}{|l|l|l|l|l|l|}
\hline Interfaces da Educ. & Paranaíba & v. 2 & n. 5 & p.84-98 & 2011 \\
\hline
\end{tabular}


A partir dos anos 20 veiculavam entre professores uma revista denominada Revista de Ensino ${ }^{8}$. Os temas tratados nessa coleção de revistas envolviam programas de ensino, orientações didáticas para o professor, textos sobre Educação, legislações, etc. Os artigos dessas revistas revelavam grande preocupação com a formação pessoal dos professores destacando a moral necessária ao bom desempenho profissional. Observamos com freqüência transcrição de Programas de Ensino vigentes, com a preocupação de que estes fossem divulgados aos professores. Também havia artigos com o foco nas metodologias de ensino.

Para este artigo, a análise realizada foi apenas das revistas que apresentavam textos que discutiam o ensino de Matemática.

Constatamos que os assuntos matemáticos que mais apareciam nessas revistas eram sobre o ensino das quatro operações aritméticas com números naturais, o ensino das "frações", e a discussão de alguns tipos de problemas. No entanto, os programas do Curso Primário da época, publicados nessas mesmas revistas, apresentavam grande quantidade de conteúdos de Geometria como é possível observar no Quadro 4.

\section{Quadro 4: Programa de Ensino para os Grupos Escolares - Secretaria Estadual de} Educação de São Paulo

Fonte: Revista de Ensino Número 2 de 1905

\begin{tabular}{|c|c|c|}
\hline & Aritmética & Geometria \\
\hline $1^{\circ}$ ano & $\begin{array}{l}\text { Rudimentos das primeiras operações } \\
\text { pelos meios concretos, com auxilio de } \\
\text { taboinhas ou de tornos de sapateiro. } \\
\text { Ler e escrever números e aprender a ler } \\
\text { os mapas de números. } \\
\text { Uso dos sinais }+, \text {, } \mathrm{x}, \text { : e =, } \\
\text { praticamente em todas as combinações. } \\
\text { As quatro operações fundamentais até } \\
100 \text {. } \\
\text { Cálculo mental. Problemas fáceis. } \\
\text { Algarismos romanos. }\end{array}$ & $\begin{array}{l}\text { Esfera, cubo, cilindro, hemisfério, } \\
\text { prisma quadrangular e triangular, } \\
\text { estudos quanto à superfície, às faces, } \\
\text { quinas ou linhas, aos cantos ou } \\
\text { ângulos. }\end{array}$ \\
\hline $2^{\circ}$ ano & $\begin{array}{l}\text { As quatro operações até } 1000 \text {, inclusive } \\
\text { conhecimentos de } 1 / 2,1 / 3,1 / 4 \text {, etc. } \\
\text { Tabuada de multiplicar e de dividir até } \\
\text { 12. Formação de unidades, dezenas, } \\
\text { centenas e milhares. Soma e subtração. } \\
\text { Multiplicação e divisão: casos simples. } \\
\text { Sistema métrico: exercícios práticos } \\
\text { sobre pesos e medidas. Cálculo mental. } \\
\text { Problemas algarismos romanos. }\end{array}$ & $\begin{array}{l}\text { Pirâmide e cone, quanto à superfície, } \\
\text { às faces, às linhas e aos ângulos. } \\
\text { Elipsóide e ovóide. Formas das faces } \\
\text { dos sólidos, nome dos ângulos e das } \\
\text { linhas que limitam a superfície. }\end{array}$ \\
\hline
\end{tabular}

\footnotetext{
${ }^{8}$ Uma coleção dessas revistas está organizada para consulta no Centro de Referência em Educação Mário Covas. Era publicada pela Associação Beneficente do Professorado Público de São Paulo
}

\begin{tabular}{|l|l|l|l|l|l|}
\hline Interfaces da Educ. & Paranaíba & v. 2 & n. 5 & p.84-98 & 2011 \\
\hline
\end{tabular}


$3^{\circ}$ ano Estudo da multiplicação e da divisão. Posição das linhas. Construção de Fração decimal: ler e escrever números perpendiculares e paralelas, de decimais, reduzir frações ao mesmo ângulos, de triângulos e do quadrado. denominador. As quatro operações com Medida de superfície do quadrado e frações decimais. Sistema métrico do retângulo. Problemas.

decimal. Exercícios práticos sobre pesos

e medidas. Cálculo mental. Problemas.

$4^{\circ}$ ano Revisão. Frações ordinárias: próprias e Avaliação da área dos triângulos, impróprias, homogêneas e heterogêneas. quadriláteros e polígonos. Redução de frações ao mesmo Circunferência e suas linhas. Circulo. denominador pelo processo geral. Construção de polígonos regulares. Adição, subtração, multiplicação e Problemas.

divisão de frações ordinárias.

Transformar frações ordinárias em decimais e vice-versa. Sistema métrico decimal. Cálculo mental. Problemas e questões práticas.

Com relação aos conteúdos de Aritmética, é importante assinalar que o destaque no $1^{\circ}$ e $2^{\circ}$ anos era para os números naturais e no $3^{\circ}$ e $4^{\circ}$ anos era para os números racionais na representação fracionária, talvez pelo uso social desses tipos de números na época. Também é importante destacar a proposta de desenvolver cálculo mental a partir do $2^{\circ}$ ano, talvez pelo predomínio do comércio, com a necessidade de efetuar cálculos e a falta de calculadoras, o uso do cálculo mental devia ser constante.

A organização dos conteúdos matemáticos proposta no Programa Oficial e a falta de publicação de artigos sobre o ensino de Geometria nos permite conjecturar que a Geometria era pouco ensinada nesse segmento de ensino nessa época.

A análise dos programas da Escola Normal de São Paulo publicada em uma das Revistas de Ensino em 1920 revela o predomínio de disciplinas de caráter geral, com foco numa cultura geral ampla, mas com pouco conhecimento das áreas que os futuros professores dos Grupos Escolares iriam ensinar.

\section{A influência da Psicologia e o denominado "paradigma perdido"}

Neste item analisaremos principalmente livros de Matemática.

A partir de 1920 identifica-se a influência da Psicologia no Curso Normal e o que Shulman (1992) denomina de "paradigma perdido".

Segundo o autor, a influência da Psicologia pode ser observada nos tópicos tratados nos textos da disciplina de Psicologia da Educação na primeira década do século XX: psicologia da aritmética, da leitura, da aprendizagem. O fenômeno que ele denomina de paradigma perdido pode ser observado quando Shulman (1992) constata que, a partir dos anos 30, esses assuntos foram sendo substituídos por tópicos gerais de ensino tais como memória, aprendizagem, motivação, tendências que perduraram até os idos de 1960.

\begin{tabular}{|l|l|l|l|l|l|}
\hline Interfaces da Educ. & Paranaíba & v. 2 & n. 5 & p.84-98 & 2011 \\
\hline
\end{tabular}




\section{INTERFACES DA EDUCAÇÃO}

No Brasil, a influência da Pedagogia e da Psicologia em detrimento dos conteúdos curriculares, objetos de ensino, foi se fortalecendo nos cursos normais com o passar dos anos e dura praticamente até os dias atuais (CURI, 2004).

Embora constatamos nas reedições do livro de Trajano uma preocupação com os conteúdos matemáticos, mesmo reduzidos à Aritmética, a influência da Psicologia provocava mudanças nos livros de Matemática destinados ao Curso Normal. O livro Psicologia da Aritmética de Thorndike (1929) foi marcante no país e influenciou várias gerações de autores de livros de Metodologia do Ensino de Matemática.

Thorndike, psicólogo americano, trabalhou com animais e entendia que todo comportamento de aprendizagem era regulado por punição e recompensa, o que ele denominava de "disciplina mental".

O prefácio do livro de Thorndike indica claramente a influência da Psicologia: "Esse livro foi escrito com a finalidade expressa de aplicar ao ensino da aritmética os princípios descobertos pela Psicologia do aprendizado, pela Pedagogia experimental e pela observação da prática escolar bem-sucedida" (THORNDIKE, 1929, p.7).

Segundo Kilpatrick (1989), Thorndike promove a idéia de que as diferenças individuais ditam a necessidade de expor as crianças a diferentes métodos de instrução.

Consideramos que o livro de Thorndike (1929) baseia-se numa concepção empíricoativista do processo ensino e aprendizagem que se opunha à Pedagogia Tradicional do final do período do Império. Na visão empírico-ativista se considera o aluno um ser ativo que se desenvolve a partir de experiências. Segundo Fiorentini (1995) nessa tendência a Matemática é ensinada pelos seus valores utilitários, suas relações com outras ciências e suas aplicações para resolver problemas. O ensino utiliza-se de atividades experiementais, resolução de problemas e método cientifico. Na tendência empírico-ativista, acredita-se que o aluno aprende fazendo, o que contrasta a visão anterior dos livros de Trajano.

Consideramos que, em conseqüência da influência da Psicologia, os autores de livros destinados ao Curso Normal preocupavam-se com a motivação no ensino, enfatizando o uso de jogos e materiais didáticos, o estudo dirigido, tendências fortes do período da Escola Nova?.

Outro livro importante da época é o de Aguayo (1935) denominado de Didática da Escola Nova. O livro foi traduzido em 1935, apresentava vários capítulos sobre tópicos gerais da Psicologia e outros sobre temas curriculares, entre eles o Ensino de Aritmética, com sugestões didáticas para os professores.

Esse autor fazia observações bastante interessantes que podem ser consideradas atuais. Destacava a importância de se respeitar a liberdade da criança na realização dos procedimentos de cálculos, a utilização de situações da vida real nos problemas aritméticos e a observação dos processos de raciocínio na resolução dos problemas ao invés da apresentação por parte dos professores de soluções dos mesmos.

\footnotetext{
${ }^{9}$ Escola Nova é um dos nomes dados a um movimento de renovação do ensino que foi especialmente forte na Europa, na América e no Brasil, na primeira metade do século XX . "Escola Ativa" ou "Escola Progressiva" são outros termos usados para descrever esse movimento. Os primeiros grandes inspiradores da Escola Nova foram o escritor Jean-Jacques Rousseau (1712-1778) e os pedagogos Heinrich Pestalozzi (1746-1827) e Freidrich Fröebel (1782-1852). O grande nome do movimento na América foi o filósofo e pedagogo John Dewey (1859-1952 No Brasil, as idéias da Escola Nova foram introduzidas já em 1882 por Rui Barbosa (1849-1923). (SAVIANI, 2000).
}

\begin{tabular}{|l|l|l|l|l|l|}
\hline Interfaces da Educ. & Paranaíba & v. 2 & n. 5 & p.84-98 & 2011 \\
\hline
\end{tabular}




\section{INTERFACES DA EDUCAÇÃO}

Analisando o prefácio de seu livro percebe-se que, em sua visão, o aluno usando sua obra torna-se ativo em sua aprendizagem e o professor deixa de ser o centro tornando-se elemento facilitador. Um fato que precisa ser destacado é a pouca importância reservada ao ensino de Geometria por esse autor que dedica menos de uma página a esse assunto, dentre as 30 páginas destinadas à Matemática. O autor informa que o ensino de Geometria se confunde com o do Desenho e não deve ir além dos exercícios e problemas que têm aplicação na vida real. Não há nenhuma orientação ao futuro professor sobre como ensinar Geometria como o autor fez com a Aritmética.

No entanto, esse autor ainda faz alguma menção ao ensino de Geometria, pois os outros livros analisados nada mencionam em relação a esse tema.

Segundo Curi (2004), a preocupação de apresentar soluções dos exercícios propostos e respostas nos livros de Matemática que os autores estudados revelaram permaneceu através dos tempos. Em sua pesquisa ela analisou livros até o final da década de 1970. Os autores de livros didáticos analisados em sua investigação chamavam a atenção dos professores para esse fato e salientavam que as soluções dos exercícios facilitavam o trabalho do professor, o que possibilita conjecturar que os professores necessitavam dessas respostas para verificar se os exercícios que resolviam estavam corretos.

\section{Considerações finais}

A análise realizada na listas de pontos para os exames do Curso Normal, a lista de temas para os concursos públicos para ser professor e a lista de conferências do livro de Barão Gérando revelam a influência do iluminismo e da Igreja na formação do professor, que primava pela regulação de condutas, comportamentos pessoais e sociais compatíveis com a monarquia instalada, com pouca preocupação para com o ensino. A formação pedagógica era limitada à disciplina Métodos de Ensino que discutia o ensino mútuo. Havia uma crença de que para ser professor bastava ler e efetuar as quatro operações, ter boa caligrafia e saber rezar.

Com a influência do positivismo, a situação se modificou. $\mathrm{O}$ rol de disciplinas do Curso Normal da Primeira República em São Paulo era bastante extenso, com muitas disciplinas. Mas os estudos das disciplinas relativas aos temas da Matemática eram similares aos conteúdos matemáticos propostos para serem ensinados. Percebe-se, a partir dos anos 20, a forte influência da Psicologia nos livros de Matemática.

O artigo corrobora os estudos de Tardif (2000) sobre a evolução dos conteúdos ensinados nas escolas e da maneira de ensinar em relação ao tempo e às mudanças da sociedade. Corrobora também os estudos de Shulman (1992) sobre o que ele denomina de "paradigma perdido". Os livros analisados revelam a mudança de foco para o "como ensinar" apontada por Shulman (1992). Um exemplo disso é o livro A nova Metodologia da aritmética, de Thorndike (1929) e este livro influenciou autores de outras décadas como Aguayo que publicou em 1956 o livro Didática ${ }^{10}$ da Escola Nova e Theobaldo de Miranda Santos (1960).

\footnotetext{
${ }^{10}$ É conveniente destacar que a denominação Didática da Matemática usada nesses manuais não corresponde às concepções mais recentes relativas aos objetos desse campo de conhecimento, mas caracteriza-se mais por seu cunho 'metodológico', com a finalidade de oferecer sugestões e modelos ao professor, para as tarefas a serem desenvolvidas em sala de aula.
}

\begin{tabular}{|l|l|l|l|l|l|}
\hline Interfaces da Educ. & Paranaíba & v. 2 & n. 5 & p.84-98 & 2011 \\
\hline
\end{tabular}


Este artigo apresenta um conjunto de aspectos que permitiram delinear um panorama amplo da organização do Curso Normal da Província de São Paulo desde seu início e, em especial, como estava contemplada a formação para ensinar Matemática nesse curso nos primeiros cem anos de sua existência.

Consideramos a necessidade de continuidade desses estudos até o período atual, pois existem muitas possibilidades de investigações na área de Educação Matemática que contemplem a relação da história com a formação inicial do professor dos anos iniciais e o ensino de Matemática.

\section{Referências}

AGUAYO, A. M. Didática da Escola Nova. São Paulo: Companhia Editora Nacional. $1^{\text {a }}$ Edição traduzida, 1935.

CURI, E. Formação de professores polivalentes: uma análise dos conhecimentos para ensinar Matemática e das crenças e atitudes que interferem na constituição desses conhecimentos. Tese de doutorado. PUC/SP, 2004.

. A matemática e os professores dos anos iniciais. São Paulo: Musa Editora, 2005.

FIORENTINI, D. Alguns modos de ver e conceber o ensino da matemática no Brasil.

Zetetiké. Ano 3, n.4 - nov. 1995, p.1-38.

DEPARTAMENTO DE ESTATÍSTICA DO ESTADO. Anuário Estatístico do Estado de

São Paulo: situação física, social e cultural. São Paulo, 1895.

KILPATRICK, J.; STANIC, G. Perspectivas históricas da resolução de problemas no currículo de matemática. In: CHARLES R. I.; SILVER, E. A. (Ed.). The teaching and assessment of mathematical problem solving. Reston: NCTM; Lawrence Erlbaum, 1989. Disponível em: <http://www.educ.fc.ul.pt/docentes/jponte/sd/textos/stanic-kilpatrick.pdf $>$. Acesso em: 20 mar. 2004.

LÜDKE, M.; ANDRÉ, M. E. D. A Pesquisa em educação: abordagens qualitativas. São Paulo: EPU, 1986.

MONARCHA, C. Escola Normal da Praça: o lado noturno das luzes. Campinas: Editora da Unicamp, 1999.

PÁDUA, E. M. Metodologia da pesquisa: abordagem teórico-prática. 7. ed. São Paulo: Papirus, 2002.

REVISTA DE ENSINO. São Paulo, v. 4, n. 2, p. 654-660, jun.1905.

ROCA DORDAL, R. Arithmetica escolar: exercícios e problemas para as escolas primarias, famílias e collegios. São Paulo: Teixera\&Irmãos, 1901.

SANTOS, T. M. Noções da didática especial. São Paulo: Nacional, 1960.

SAVIANI, D. Escola e democracia. 33. ed. rev. Campinas: Autores Associados, 2000. SHULMAN, L. Renewing the pedagogy of teacher education: the impact of subjectspecific conceptions of teaching. In: MESA, L. Montero; JEREMIAS, J. M. Vaz. Las didácticas específicas en la formación del profesorado. Santiago de Compostela; Tórculo, 1992.

SOUZA REIS, O. Quinhentas expressões fraccionarias: para pratica do calculo aritmetico das quatro operações fundamentaes. Rio de Janeiro: Francisco Alves, 1919.

TANURI, L. M. História da formação de professores. 500 anos de Educação Escolar. Revista Brasileira de Educação, São Paulo: ANPED, n. 14, maio-ago. 2000.

\begin{tabular}{|l|l|l|l|l|l|}
\hline Interfaces da Educ. & Paranaíba & v. 2 & n. 5 & p.84-98 & 2011 \\
\hline
\end{tabular}


TARDIF, M. Saberes profissionais dos professores e conhecimentos universitários: elementos para uma epistemologia da prática profissional dos professores e suas consequencias em relação à formação para o magistério. Revista Brasileira da Educação, São Paulo: ANPED, n.13, jan.-abr. 2000.

TRAJANO, A. Arithmetica progressiva. Rio de Janeiro: Livraria Francisco Alves, 1880. THORNDIKE, E. L. A nova metodologia da aritmética. Porto Alegre: Globo, 1929. 